\title{
THE VALUE OF THE AGGLUTINATION REACTION AND OF BACTERIOLOGICAL METHODS IN THE DIAGNOSIS OF GLANDERS.*
}

\author{
K. R. COLIINS.
}

(From the Research Laboratory, Depariment of Heallh, New York Cily.)

THE readiness with which the agglutination test can be carried out when compared with the mallein test for glanders has made it the subject of much investigation by those interested in comparative medicine. In attempting to establish the agglutination test as a routine method of diagnosis we were confronted by many questionable cases that proved puzzling to the diagnostician, and although the delicacy and specificity of the reaction seemed to be very well established by many observers it was deemed advisable to undertake a thorough study of the method with the hope of coming to some practical conclusion as to the disposition of these anomolous cases. Therefore while very little that is new is here presented our experience may prove of some interest and value in the practical application of the test. In confirming the results of the test by bacteriological findings some new facts were developed that have not heretofore been mentioned by any of the observers along these lines.

During the course of this work all clinical observations and autopsies have been made and blood specimens furnished by Dr. H. D. Gill, veterinarian for the State Department of Health, New York, Dr. K. S. Silkman, veterinarian for the Department of Health, New York City, and Dr. R. H. Kingston, New York City. Dr. E. P. Miller and Dr. R. E. Pick have also rendered valuable assistance in the routine testing.

After following the application of this reaction for over two years, during which time about 2,500 horses of all classes have been tested, the results, in our opinion, are not so conclusive from a practical standpoint as to make it a means of absolute diagnosis.

This difference of opinion is not wholly due to the use of different methods, as at first might be assumed, for while the microscopical

* Received for publication May 30, 1908. 
method has been relied upon for the routine work, the macroscopical method of Schütz and Meissner ${ }^{\mathrm{I}}$ has been systematically employed as control in a large number of cases, and we have found the same exceptions occurring with both methods. Some of the points of difference between the two methods and our reason for considering that the microscopical method gives the best results will be dealt with later.

Pokchichevski $^{2}$ in 1902 found that normal horse blood would agglutinate the $B$. malle $i$ in dilutions of $\mathrm{x}: 300$, while the blood of horses infected with glanders would agglutinate it in dilutions of I : 500 and above.

Afanassjeff, ${ }^{3}$ Schnürrer, ${ }^{4}$ and Bonomé ${ }^{5}$ confirmed these results, while Hutyra,${ }^{6}$ inducing experimental glanders in horses, found that the agglutination index ranging from $I: 100$ and $I: 300$ before injection of $B$. malle $i$ was raised to $I: I, 000$ and $I: 2,000$ several days after inoculation.

Schütz and Meissner of the Pathological Institution, Berlin, in 1905 undertook an extensive series of observations upon the subject. A number of horses were given experimental glanders and in from 6 to 12 days after infection the agglutinating index of the blood serum of these horses had increased from $I: 300$ to $I: 2,000$ and 8,000 . Subsequent autopsy of these showed the typical lesions of glanders in the lungs and other organs. In the course of their work 2,209 horses were tested. This number included normal horses, horses having glanders, and those ill of other diseases than glanders.

The following table gives a very good average of the results they obtained, and from these tables it will be seen that 48 horses out of 238 which were glanders-free reacted at a point that is considered by them to be diagnostic of glanders. Out of 37 horses having various diseases other than glanders they give to as reacting between I:500 and $I: I, 000$. These tables are quoted in order to show that although Schütz and Meissner used the macroscopical method

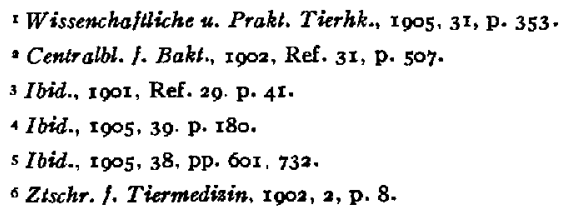


throughout their work, while we used the microscopical method, yet they find that the normal index may sometimes be as high as I,, 00 , while on the other hand a certain percentage of horses having glanders will react as low as 500 .

TABLE ז.

Aggudtnation or B. mallei by Serum of Normal and Diseased Horses. (Schttrz and Meissner.)

\begin{tabular}{|c|c|c|c|c|c|c|c|c|c|c|c|}
\hline \multicolumn{6}{|c|}{ Glanders-Free } & \multicolumn{6}{|c|}{ Glanders } \\
\hline$r: 300$ & 400 & 500 & 600 & 800 & $1, \infty 00$ & 500 & 600 & 800 & $1, \infty \infty$ & $I_{1} 500$ & $2, \infty 00$ \\
\hline 145 & 36 & I & $\mathbf{I} 5$ & 6 & 2 & 2 & 4 & 6 & II & 6 & 6 \\
\hline \multicolumn{6}{|c|}{221 (25 dead) } & \multicolumn{6}{|c|}{34} \\
\hline
\end{tabular}

TABLE 2 .

Agglutination of $B$. mallei by Serum of Normal and Glandered Horses. (SchttrZ AND MEISSNER.)

\begin{tabular}{|c|c|c|c|c|c|c|c|c|c|c|c|}
\hline \multicolumn{6}{|c|}{ Glanders-Free } & \multicolumn{6}{|c|}{ Glanders } \\
\hline$I: 300$ & 400 & 500 & 600 & 800 & $1, \infty \infty$ & 500 & 600 & 800 & 1,000 & $\mathbf{I}, 500$ & $2, \infty 00$ \\
\hline 5 & 4 & 2 & $\mathbf{I}$ & 4 & $I$ & $\cdots$ & 2 & 2 & 4 & 9 & 2 \\
\hline \multicolumn{6}{|c|}{ I 7} & \multicolumn{6}{|c|}{ I9 } \\
\hline
\end{tabular}

(36 horses.)

We have also found that it is not possible to determine an absolute boundary between the normal and the infected horse that will not at times prove unsatisfactory; our experience has led us, however, to adopt the usual index of 500 as the lowest to indicate infection. The exceptions to this will be given later.

In considering the method to be used in making these tests we found the microscopical method to be more satisfactory than the method of Schütz and Meissner for the following reasons:

First, Schütz and Meissner submit the emulsion of the bacillus to $60^{\circ}$ of heat for two hours; this tends lo break up the bodies of the bacilli and to release the precipitable substances, so that the phenomenon would partake more of the nature of a precipitin rather than of an agglutinin reaction. As is well known, the precipitins are not formed in the blood to the same extent as the agglutinins, so a different range of index would be required for the two reactions; the index limit for precipitins being considerably lower than for 
agglutinins in the same serum. The confusion of these two reactions does not seem to us to add to the uniformity of the test, as the relation between precipitin and agglutinin is not constant but varies in different immune sera.

Secondly, while the readings of the microscopical method average higher than the macroscopical method, yet by the former method we find fewer horses exhibiting clinical and other symptoms of glanders falling below $\mathrm{r}: 500$ in their agglutinating index, thus rendering the latter method less reliable where more definite indications are absent. The microscopical will therefore bring under suspicion a greater number of perhaps questionable horses to be tested with mallein and thus fewer actual cases will be overlooked.

The following table presents a fair average of the difference observed in all cases tested by the two methods. As we rely upon the agglutination test chiefly as an indication for the use of mallein it is quite obvious that in such instances the advantage lies with the microscopical test.

TABLE 3 .

Tee Sera of five Horses Tested Both by the Microscopical and Macroscopical Meteods.

\begin{tabular}{|c|c|c|c|c|c|c|c|c|c|}
\hline Number & 100 & 200 & 500 & $1, \infty \infty$ & 2,000 & 5,000 & 10,000 & $\underset{\text { Test }}{\text { Mallein }}$ & $\begin{array}{c}\text { Final Dis- } \\
\text { position }\end{array}$ \\
\hline $9\left\{\begin{array}{l}\text { Mic.......... } \\
\text { Mac....... }\end{array}\right.$ & ++ & + & ++ & $+t$ & +4 & ++ & & Negative & Working \\
\hline $\operatorname{ro}\left\{\begin{array}{l}\text { Mic........... } \\
\text { Mac..... }\end{array}\right.$ & ++ & ++ & ++ & ++ & ++ & ++ & + & Positive & Destroyed \\
\hline A $\left\{\begin{array}{l}\text { Mic........ } \\
\text { Mac...... }\end{array}\right.$ & ++ & ++ & $+t$ & ++ & ++ & ++ & ++ & "، & $" 4$ \\
\hline B $\left\{\begin{array}{l}\text { Mic.......... } \\
\text { Mac...... }\end{array}\right.$ & ++ & ++ & ++ & $+t$ & ++ & ++ & ++ & “" & "“ \\
\hline $\mathrm{C}\left\{\begin{array}{l}\text { Mic.......... } \\
\text { Mac....... }\end{array}\right.$ & $+t$ & $+t$ & + & + & ++ & ++ & - & $" 4$ & 4 \\
\hline
\end{tabular}

It is claimed by Bonomé that mallein increases the index. This change we found not to be constant, but on the other hand to vary. Horses tested the first 24 hours after the injection of mallein gave an agglutinating index that was slightly lowered, but tests made subsequent to this were so irregular that we were unable to convince ourselves that the changes were due to the effect of mallein instead of the progress of the disease.

A series of tests made upon four horses show the variation in the 
agglutination reaction that may sometimes occur. In the table below a regular increase is observed in three, while the third shows an irregular rise and fall. This condition occurs constantly in experimental animals immunized with various organisms.

TABLE 4.

\begin{tabular}{|c|c|c|c|c|c|c|}
\hline \multicolumn{3}{|c|}{ Frrst Test } & \multicolumn{2}{|c|}{ Second Test } & \multicolumn{2}{|c|}{ THIRD Test } \\
\hline Horse & $\begin{array}{l}\text { Aggluti- } \\
\text { nation }\end{array}$ & Mallein & Agglutination & Mallein & Agglutination & Mallein \\
\hline $\begin{array}{l}1 \ldots \ldots \ldots \\
2 \ldots \ldots \ldots \\
3 \ldots \ldots \ldots \\
4 \ldots \ldots \ldots\end{array}$ & $\begin{array}{l}5,00 \\
5,000 \\
2,000 \\
2,000\end{array}$ & $\begin{array}{l}\text { Positive } \\
\text { Positive } \\
\text { Good } \\
\text { Good }\end{array}$ & $\begin{array}{l}2 \text { weeks later, } 2,000 \\
2 \text { weeks later, 10,000 } \\
5 \text { weeks later, } 5,000 \\
5 \text { weeks later, } 5,000\end{array}$ & $\begin{array}{l}\text { Positive } \\
\text { Positive } \\
\text { Good } \\
\quad \ldots \ldots\end{array}$ & $\begin{array}{l}2 \text { weeks later, } 10,000 \\
\ldots \ldots \ldots \ldots \ldots \ldots \\
\text { 10 days later, } 2,000 \\
5,000\end{array}$ & $\begin{array}{c}\text { Positive } \\
\ldots \ldots \\
\text { Good }\end{array}$ \\
\hline
\end{tabular}

Meissner and Schütz found that the blood of one horse with lymphangitis, out of four tested, agglutinated at $I: I, \infty 00$ and two at $I: 800$. They state that this is the only condition, not glanders, that will give such a high reaction.

Nine horses with lymphangitis were tested by us, and mallein was given to four.

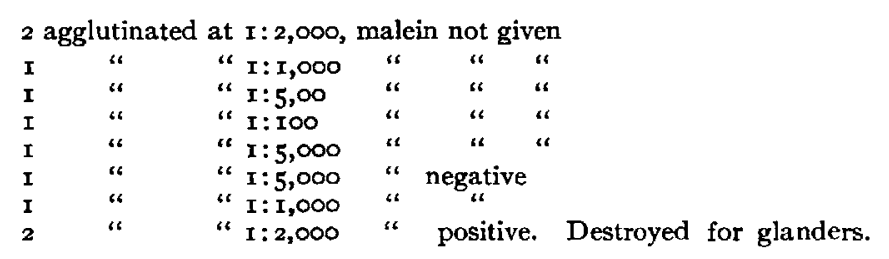

The question that might arise here is whether or not there was a latent glanders in those cases where the reaction is high. More extensive research is necessary before any conclusion can be reached, but the fact that two horses apparently free from glanders reacted to mallein is suggestive. The mallein was not given until the horses had fully recovered from the attack of lymphangitis.

The practice has been followed of taking a stable where the horses are permanent and testing the blood of all horses, then giving mallein to as many as possible and keeping the stable under obsertion for some time.

In one stable consisting of 32 horses where glanders had occurred the reactions were as follows: 


$\begin{array}{ccc}\text { Number of Horses } & \text { Agglutinating Index } & \text { Number Reacted to Mallein } \\ 4 & 500 & 2 \\ \text { I } 2 & \text { Between 1,000-2,000 } & 6 \\ 7 & \text { " } 5,000-10,000 & 3 \\ 9 & \text { Below 500 } & \text { None }\end{array}$

In another stable containing sixty horses the results were as follows:

$\begin{array}{cc}\text { Number of Horses } & \begin{array}{c}\text { Agglutination } \\ \text { Reaction }\end{array} \\ 9 & 500 \\ 9 & 1,000 \\ 7 & 2,000 \\ 35 & \text { Below } 500\end{array}$

$\begin{array}{cc}\begin{array}{c}\text { Number of } \\ \text { Horses Tested } \\ \text { with Mallein }\end{array} & \begin{array}{c}\text { Number Reacted } \\ \text { to Mallein }\end{array} \\ 3 & 2 \\ 6 & 3 \\ 4 & 4 \\ 2 & 2 \text { negative }\end{array}$

In this case 9 out of $\mathrm{I}_{3}$ horses agglutinating above 500 reacted to mallein. We were not able to follow this stable.

The table below gives the results of the agglutination test of 49 horses. All the horses with the exception of 16 which showed definite characteristic symptoms of glanders were tested with mallein.

TABLE 5.

aggutunation Reaction of Horses to $B$. mallei.

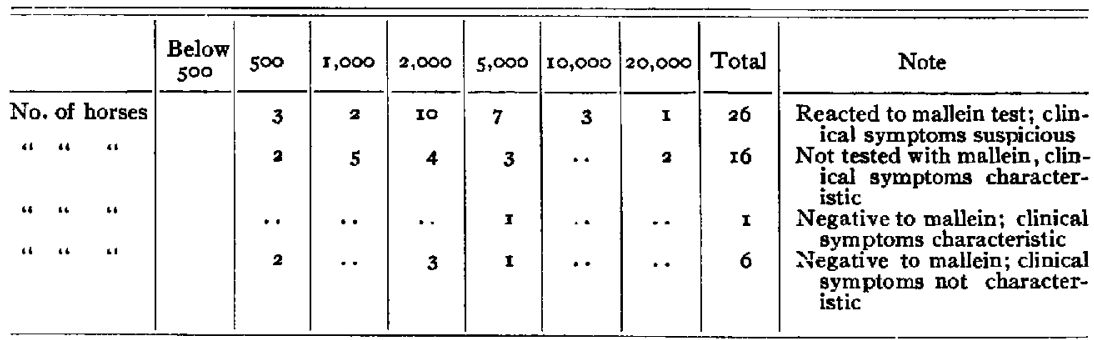

In a stable of 16 horses three of which had died of glanders we were able to follow up the agglutination and mallein reactions by autopsy. Our observations extended over a period of four months. Table 6 shows the relation of the agglutination test and the mallein reaction and autopsy findings.

In case No. I, although all definite symptoms are absent, the very marked and sudden rise of agglutinins would indicate very strongly a glanders infection. Pus from an external ulcer did not develop the Straus reaction in guinea-pigs.

No. 6 probably comes under the exceptional cases that show a lowered index in the last stages of the disease. 
We have found about three cases per $x, 000$ falling below 500 that have shown definite symptoms of glanders and are in the last stages of the disease.

TABLE 6 .

Rejation of Agglutination and Mallein Tests to Autopsy Findings.

\begin{tabular}{|c|c|c|c|c|c|c|c|c|c|}
\hline \multirow{2}{*}{ HORSFS } & \multicolumn{2}{|c|}{ October } & \multicolumn{2}{|c|}{ November } & \multicolumn{2}{|c|}{ December } & \multicolumn{2}{|c|}{ JANUARY } & \multirow{2}{*}{ RESULTS OF AUTOPSY } \\
\hline & $\begin{array}{c}\text { Aggluti- } \\
\text { nation }\end{array}$ & $\begin{array}{l}\text { Mal- } \\
\text { lein }\end{array}$ & $\begin{array}{l}\text { Aggluti- } \\
\text { nation }\end{array}$ & $\begin{array}{l}\text { Mal- } \\
\text { lein }\end{array}$ & $\begin{array}{c}\text { Aggluti- } \\
\text { nation }\end{array}$ & $\begin{array}{l}\text { Mal- } \\
\text { lein }\end{array}$ & $\begin{array}{l}\text { Aggluti- } \\
\text { nation }\end{array}$ & $\begin{array}{l}\text { Mal- } \\
\text { lein }\end{array}$ & \\
\hline & & & 200 & $\ldots .$. & 200 & Neg. & $5,000 *$ & Neg. & No lesions on autopsy \\
\hline & $\begin{array}{l}5,000 \\
5,000\end{array}$ & $\begin{array}{l}\text { Neg- } \\
\cdots .\end{array}$ & $\begin{array}{l}\ldots, 000 \\
5,000\end{array}$ & $\ldots \ldots$ & $\begin{array}{r}5,000 \\
10,000\end{array}$ & Pos. & To,0 & Po & $\begin{array}{l}\text { Died of glanders } \\
\text { Killed; lesions characte }\end{array}$ \\
\hline & & & & & & & & & istic of glanders \\
\hline $4 \cdots$ & 5,000 & $\cdots \cdots$ & $2, \infty \infty$ & $\cdots \cdots$ & 10,000 & Pos. & $\cdots \cdots$ & $\cdots \cdots$ & $\begin{array}{l}\text { Killed; lesinns character- } \\
\text { istic of glanders }\end{array}$ \\
\hline st.... & $\cdots \cdots$ & & & & 500 & Pos. & $\cdots \cdots$ & & Killed; lesions character- \\
\hline $6 \mp \ldots$ & $\cdots \cdots$ & $\ldots$. & $\cdots \cdots$ & $\cdots \cdots$ & 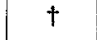 & Pos. & $\cdots \cdots$ & & Killed; lessions character. \\
\hline $7 \ldots$ & $\cdots \cdots$ & $\cdots \cdots$ & 500 & $\cdots$ & 500 & Pos. & $\cdots$ & & Killed; lesions character- \\
\hline $8 \ldots$. & & & & & 10,000 & Pos. & & & Killed: lesions character- \\
\hline & $\ldots$. & $\cdots \cdots$ & $\cdots \cdots$ & $\ldots$. & Neg. & Neg. & $\cdots$ & & Killed; no lesions \\
\hline & & & & & 10,000 & & $\cdots \cdots$ & & $\begin{array}{l}\text { Killed; lesions character- } \\
\text { istic of glanders }\end{array}$ \\
\hline $11 \ldots$. & $\cdots \cdots$ & $\cdots \cdots$ & $2, \infty 00$ & & $\mathbf{r}, 000$ & Pos. on & & & $\begin{array}{l}\text { Killed; lesions character- } \\
\text { istic but not marked }\end{array}$ \\
\hline $12 \ldots$ & $\cdots \cdots$ & $\cdots \cdots$ & 5,000 & $\cdots \cdots$ & 5,000 & Pos. & … & ...... & Killed; lesions character- \\
\hline I3. & $\cdots \cdots$ & $\ldots \ldots$ & ..... & .... & 1,000 & Pos. & & $\cdots$ & Died of glanders \\
\hline
\end{tabular}

* This horse developed an ulcer on the leg and the second day the blood was tested with the results given above.

† Skin lesions appeared on the lower maxillary a few hours before killed.

¥ This horse had been immunized for a period of two years with typhoid, dysentery, pneumococcus cholera, and tetanus respectively.

One of the possible causes of a lowered index in the final stages is the invasion of other organisms which, supplanting the infecting organism, form agglutinins or other anti-bodies which affect the agglutinins, as was shown by Klein who caused the agglutinins in rabbits immunized to $B$. typhi to disappear by discontinuing the inoculation of the typhoid bacillus and substituting that of cholera.

In estimating the reliability of the agglutination reaction as an independent means of diagnosis several factors must be taken into consideration. In reviewing the results as given in the above tables the weight of evidence certainly seems to indicate that a reaction above 500 indicates a glanders infection, either latent or active according to the other symptoms present.

This conclusion as to the specificity of the reaction is further 
borne out by the absorption test and animal inoculations. A number of organisms found in the superficial ulcers, in material from the lungs, glands, and nasal secretions associated in many cases with B. mallei, were isolated. These failed to absorb out the agglutinins: they also failed to raise agglutinins for the $B$. malle $i$ when inoculated into rabbits and only one organism produced agglutinins for itself. Therefore such organisms, as far as tested, could not give rise to the agglutinins for B. mallei.

Hutyra found in experimental glanders that the agglutination reaction appeared before the mallein reaction, thus making a more delicate test. So when the reaction is 500 and above, becoming more certain as it increases, it seems justifiable to assume that even in the absence of other symptoms a slight infection exists which may remain latent for some time and later recover or go on to a full development of the disease. The similarity of this disease, in many of its phases, to tuberculosis is marked and there is no reason why we should not assume that recovery may take place.

It is well known that even after reacting to mallein a horse may remain in good condition for some years. One horse whose history we were fortunate enough to obtain had two years previously reacted to mallein, but as he was in good condition he was not destroyed. When brought to our notice he gave a mallein reaction and a blood reaction of 2,000, and on autopsy old lesions were found as well as fresh ones. In spite of these very suggestive results we find a number of horses in apparently good health giving a high agglutination reaction to $B$. mullei and giving no other evidence of infection. The destruction of such horses, considering the number of them, does not seem to be justifiable at present. We have had some of these high reactors under observation for the past I8 months. They have continued working and are appartenly normal and glanders has not occurred during this time among the other horses in the same stable. It does not seem practical to destroy such horses unless some compensation can be offered their owners, as it would sometimes mean a loss of 25 to 40 per cent. But it is possible often to watch these cases and have them tested from time to time.

The serum in human cases of glanders as far as tested generally reacts in dilutions of $I: I, 000$ and $r: 2,000$. 
McFadyean ${ }^{\mathrm{I}}$ found that blood of patients having diphtheria and scarlet fever would agglutinate the glanders bacillus in dilutions of $\mathrm{I}: 50$ and $\mathrm{I}: \mathrm{ro0}$. We found that normal human serum did the same, as did also serum from patients having typhoid fever and tuberculosis, while the serum of cases of glanders infection agglutinated as high as $I: I, 000$ and $I: 2,000$, unless the course of the disease was very rapid, extending over a period of three to five days. In such cases sufficient length of time has not elapsed for the agglutinins to be formed and the severe intoxication would prevent the cells from reacting.

Our failure always to recover the organism from material obtained from doubtful cases of glanders led us to make the following observations concerning the readiness with which the $B$. mallei is supplanted by the various organisms found in the glandered tissue. This was tested by growing the $B$. malle $i$ in combination with several of these organisms; also growing each organism separately and combining just before inoculation into pigs, and plating; and growing them together in a mixture. The pigs inoculated with the 24 hours' mixed growth gave a negative Straus reaction, and the $B$. malle $i$ was not recovered from the plates made from this mixture, while the separate cultures combined at time of inoculation produced an carly Straus reaction and the $B$. malle $i$ was readily isolated from the plates. This would explain the failures, that sometimes occur, to obtain bacteriological evidence of the presence of the glanders bacillus in the suppurative lesions of a horse that has glanders.

In the inoculation of suspected glandered material into guineapigs an anomalous Straus reaction was constantly encountered which was quite misleading. After 48 to 72 hours, following intraperitoneal injection, there would develop an apparent beginning Straus reaction, which would remain stationary or retrogress and finally disappear entirely. There would be sometimes a bilateral and sometimes a unilateral descent of the testicle with marked enlargement; generally the organ was reducible under pressure but slipped back as soon as the pressure was removed. This was more noticeable in the bilateral cases. Autopsy revealed an enlarged testicle hyperemic with more or less sclerosis and marked injection of the scrotal tissue

× Jour. Comp. Path. and Therap, r8g6, 9, pr 322. 
and sometimes adhesions, but no abscess formation or caseation. Nicolle $^{I}$ found that heated cultures of $B$. mallei produced anomalous reactions and from his experiments was led to describe the following successive symptoms: first, paralysis of the testicle which ceases to return spontaneously into the abdomen, edema of the scrotal tissues, definite fixation and abscess formation, followed by ulceration. With a non-fatal dose of the killed culture he was able to bring about the first stage of the reaction. We were able also to bring about this reaction not only with killed cultures but with suspected material and by the intraperitoneal injection of the filtered products of $B$. malle $i$, unheated, and of three days' growth; also with mallein; and in three instances with the serum of animals having undoubted glanders.

This last phenomenon is, according to our experience, rare, and would seem to depend upon the large amounts of endotoxins in the blood of the animal. The organism was not found in the blood in these cases. The animals tested were all severe cases of glanders, as proven by the mallein test and autopsy. Serum from normal horses failed to give this reaction. The filtered products of pyocyaneus and other organisms frequently associated with the glanders bacillus also fail to react. This suggests the possibility of the action being due to a toxin or endotoxin which is selective in its nature, acting upon this peculiar nerve structure, inducing the paralytic stage, and thus rendering the organ sensitive to the subsequent action of the bacillus itself in producing abscess.

This dual action seems to be emphasized by the fact that at times the infection may be more general or localized in other tissues, suggesting the possibility of a variation in the amount of toxin introduced at the time of inoculation. In the female, where this same peculiar nerve structure does not exist, the infection is general or localized in the glandular or peritoneal tissue.

The examination of the nasal secretion may sometimes furnish evidence of the existing disease but the presence of other organisms overgrowing $B$. malle $i$ makes the test reliable only when positive. It should be resorted to, however, in all doubtful cases as it offers one more means of diagnosis. In obtaining material from the mucous membrane of the nasal cavity we use a long sterile swab made of 
heavy iron wire and wrapped with cotton which enables us to obtain material rather high up in the nostril.

\section{SUMMARY.}

I. The serum of horses reacting with $B$. mallei in dilutions of I :,,$\infty 00$ and above indicates a glanders infection which may be latent or active according to the accompanying. symptoms and reaction to mallein.

2. Horses giving a reaction of $I: 500$ to $I: 1,000$ are to be suspected and should be tested with mallein; if no reaction occurs and the horse is apparently in healthy condition, it may be considered free from glanders.

3. A few cases, about 3 in $\mathrm{r}, 000$, will give a reaction below 500 and yet respond to the mallein test. Such horses generally give clinical evidences of glanders.

4. Horses giving a positive reaction, that are apparently in good health and fail to react to mallein, do not seem a menace to other horses about them, but should be kept under observation and tested from time to time both for the agglutination and mallein reaction. The secretion of the throat and nose of such horses should be examined for the presence of the glanders bacillus.

5. The presence of other bacilli in the tissues of a horse dying with glanders may interfere with the appearance of a Straus reaction in a guinea-pig inoculated with such post-mortem material.

6. When a guinea-pig is inoculated with post-mortem material which has become saturated with toxins and contains only a few living glanders bacilli, due to the presence of other invading organisms of a pyogenic nature, the paralytic stage of the Straus reaction only results.

7. In a few instances this paralytic stage may follow the inoculations of serum from horses having well-developed glanders.

8. This paralytic stage is brought about by the inoculation of mallein, filtrate of $B$. mallei broth culture, but not by filtrate from pyocyaneus broth cultures.

9. In human cases a reaction above Ioo would undoubtedly mean glanders. 